1733. Gruber. Grading

https://doi.org/10.30953/tmt.v1.49

Page 1 of 23

\title{
Grading Obamacare, While Speculating About Trump: Separating Fact from
} Fiction

David Gruber and Peter Urbanowicz

Editor's note: Changes (some predict repeal) in the Affordable Care Act is an immanent prospect that will affect all stakeholders in healthcare, including patients, providers, and innovators in telemedicine. In this article, David Gruber and Peter Urbanowicz inform our readers and, hopefully, help prepare them for changes that may be every bit as impactful in 2017 as were the initiating events that occurred seven years ago on March $23^{\text {rd }}, 2010$.

Table of Contents

\section{Introduction}

\section{Grading Obamacare: Coverage Without Cost Containment}

\section{"Trumpcare": What's Next?}

The First 60 Days to Six Months

Our Prediction

Winners and Losers

In Summary

References

\section{Introduction}

This article is part of a series of articles published in Telehealth and Medicine Today on the prospect of healthcare "re-reform." ${ }^{1,2,3}$ In this article, we evaluate and grade Obamacare, speculate about the emerging Republican replacement plan and provide context to the evolving debate based on data-driven fundamentals of healthcare delivery. Likely "winners and losers" by stakeholder are also identified. Whatever the outcome of PPACA "repeal and replace," Alvarez \& Marsal (A\&M) believes that another reform debate, focused solely on health insurance coverage and payment for such coverage, will not adequately address the root cause of rising healthcare costs and 
1733. Gruber. Grading

https://doi.org/10.30953/tmt.v1.49

Page 2 of 23

attendant rises in health insurance premiums, i.e., an inefficient and ineffective care delivery system that on an age-adjusted per capita basis is $50 \%$ to $75 \%$ more expensive than that of other Organization for Economic Co-operation and Development (OECD) nations.

\section{Grading Obamacare: Coverage Without Cost Containment}

In 2016, healthcare expenditures are forecast to approach $\$ 3.4$ trillion and represent $18.1 \%$ of the gross domestic product (GDP). The Centers for Medicare \& Medicaid Services (CMS) forecasts spending of $\$ 5.6$ trillion by 2025 , an increase of $\$ 2.2$ trillion within a decade.

The federal government currently spends $\$ 646$ billion on Medicare and $\$ 340$ billion on its Medicaid contribution; state expenditures on Medicaid represent an additional \$205 billion. The Children's Health Insurance Program (Titles XIX and XXI), Department of Defense, Department of Veterans' Affairs, Indian Health Service, Substance Abuse and Mental Health Services Agency (SAMHSA) and other programs represent another $\$ 400+$ billion. In aggregate, $\$ 1.6$ trillion or nearly one-half of national health expenditures are funded by federal, state and local governments. ${ }^{4}$

It is important to recognize that government involvement in the large and often dysfunctional U.S. healthcare delivery system has been long-standing since the inception of Medicare and Medicaid in $1965 .{ }^{5}$ The PPACA represents only one step, albeit an important one, in the evolution of care delivery. Any changes to the PPACA by the new Congress and Trump administration will represent the next iteration.

Prudent public policy formation would suggest that any repeal and replacement of the PPACA should consider those provisions that have succeeded and those that have failed. Below we have attempted to provide a fact-based rationale for grading the impact of the PPACA on expanding healthcare insurance coverage and cost containment. We also grade access and affordability, variables that are intimately related to the implied benefit associated with insurance coverage. 
The essence of Obamacare is coverage; the number of uninsured Americans declined by $35 \%$ from 41.0 to 28.5 million in 2013-2015 (Figure 1.). This number is forecast to fluctuate no more than $+/-2$ million by 2025 , assuming no legislative or regulatory changes.

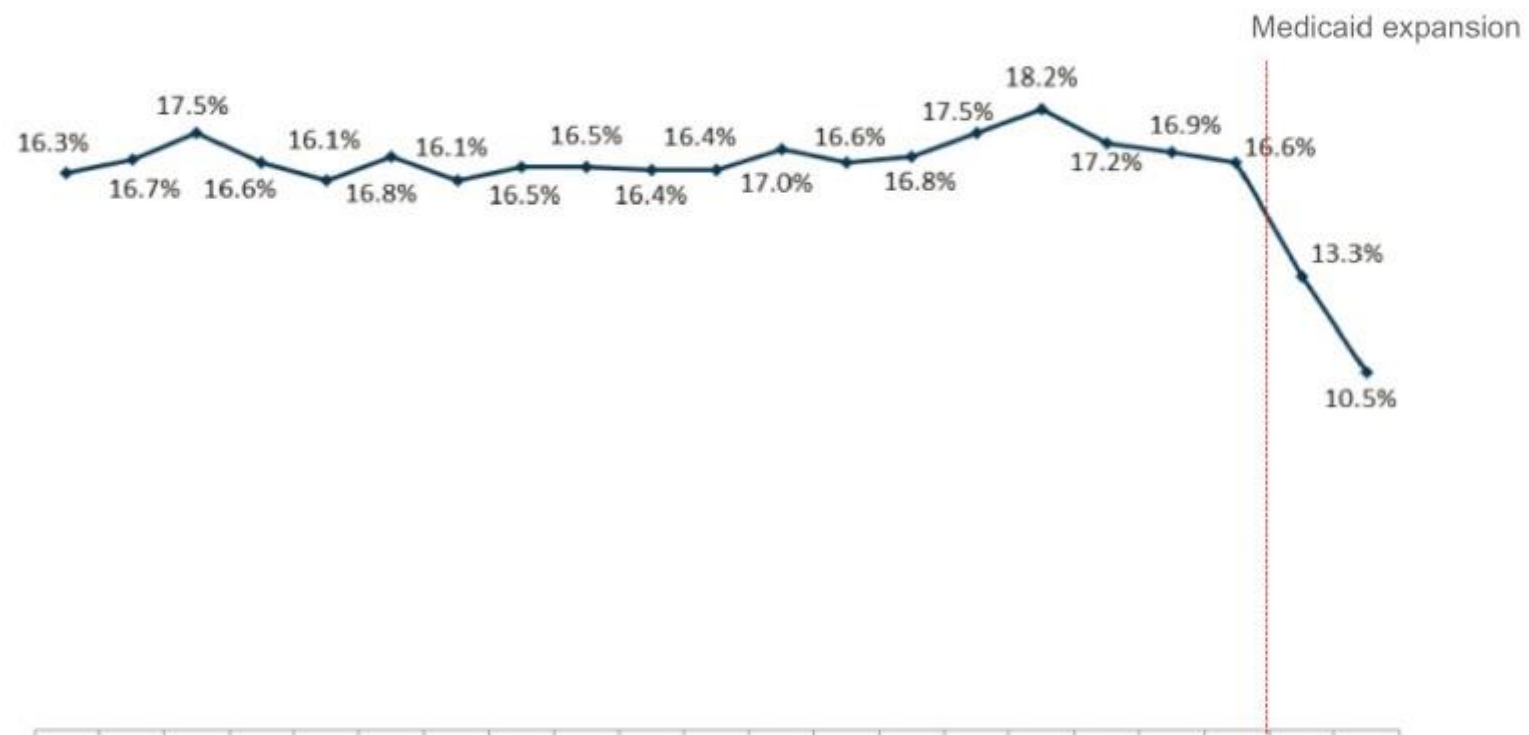

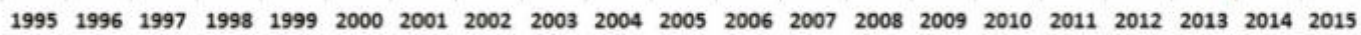

Figure 1. Uninsured rate among the nonelderly population, 1995-2015.

As of March 2016, more than 11 million people were enrolled in state or federal Marketplace plans, and as of June 2016, Medicaid enrollment had grown by more than 15 million (27\%) since the period before open enrollment (which started in October 2013). ${ }^{6}$ Note, however, that the health exchange participation figures are significantly below earlier CMS and Congressional Budget Office (CBO) expectations, which estimated that by 2016, 33 million Americans would be newly covered, with Medicaid enrollment exceeding expectation by 5 million and health exchange enrollment below expectation by 12 million. ${ }^{7}$ 
For the entire 2017-2026 period, the incremental federal spending for people who the PPACA made eligible for Medicaid coverage is projected to be $\$ 100$ billion per year, whereas the comparable figure for premium exchange subsidies is $\$ 90$ billion; in total, this equals $\$ 190$ billion in incremental federal healthcare spending per annum. ${ }^{67}$

Increased Medicaid and insurance coverage has somewhat increased provider access, especially relative to those who remain uninsured. Increased funding for Federally Qualified Health Centers (FQHC), combined with expanded hours at certain facilities, has helped. However, significant barriers to access to care remain for Medicaid beneficiaries and individuals with health exchange purchased insurance:

- Growing shortage of physicians, estimated by the American Association of Medical Colleges at 46,000-90,000 in 2025

- Inadequate number of network providers, especially specialists in exchange plans and Medicaid

- Limited acceptability of Medicaid by physicians and non-physician providers

- Patients without an identified primary care provider

- Restricted availability of (timely) appointments

- Limited provider proximity and/or excessive transportation costs

Affordability of care is the major barrier to access. Rising out-of-pocket expenses driven by higher premiums, coinsurance, copayments and, especially, deductibles represent financial challenges to many Americans (Figure 2). The PPACA has contributed both to premium increases and higher copayments and coinsurance not only for Americans newly covered under the PPACA who are participating in exchange products, but for Americans who had already been covered by employer-based coverage or by their own individual insurance. Nearly three-quarters of households have income below $\$ 97,000$ per annum — the family of four maximum for health exchange subsidies. The average household income was $\$ 55,755$ in $2015 .{ }^{8}$ 


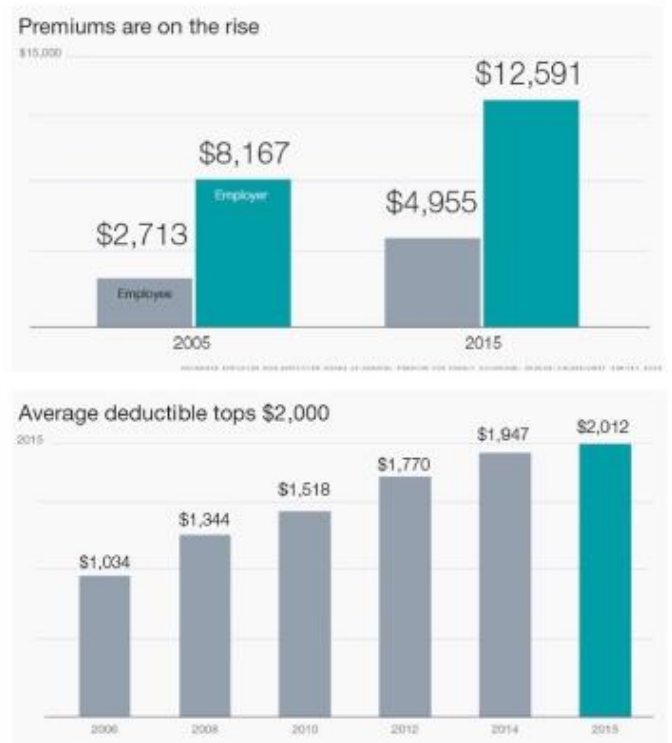

PERCENTAGE OF COVERED WORKERS ENROLLED IN AN HDHP/HRA OR HAS-QUALIFIED HDHP, 2006-2015

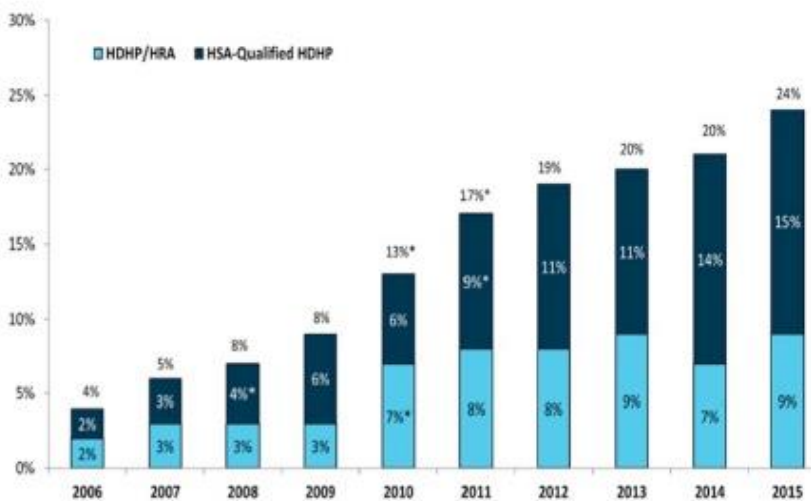

"Istmute is statistically different from estimute for the pereicus year shown ipc.05)

NOTE: Covered Wothers enrolied in an HOHP/SO are enroled in either an HOHPMRRA Cr a HSA Qualfied HOHP, For more informaticon see the

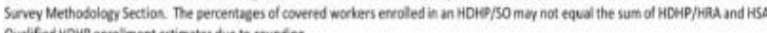

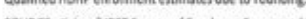

SOURCE: Kaber/MRET Surver of Enploper-Sponsored Health Benefits, 2006-2015.

Source: Kaiser/HRET Survey, 2015

Figure 2. Rising out-of-pocket expenses.

The Commonwealth Fund has developed a Health Care Affordability Index based on premium, deductible and out-of-pocket costs (Figure 3). One-quarter of all privately insured adults have high healthcare cost burdens. In a 2015 survey, $26 \%$ of Americans described healthcare costs as causing a serious financial problem during the prior two years, $27 \%$ describe being unable to pay for necessities like food, heat or housing, and $42 \%$ mention spending all or most of their personal savings. ${ }^{9}$ Healthcare costs are a major contributor, if not the leading factor, associated with personal bankruptcy. 

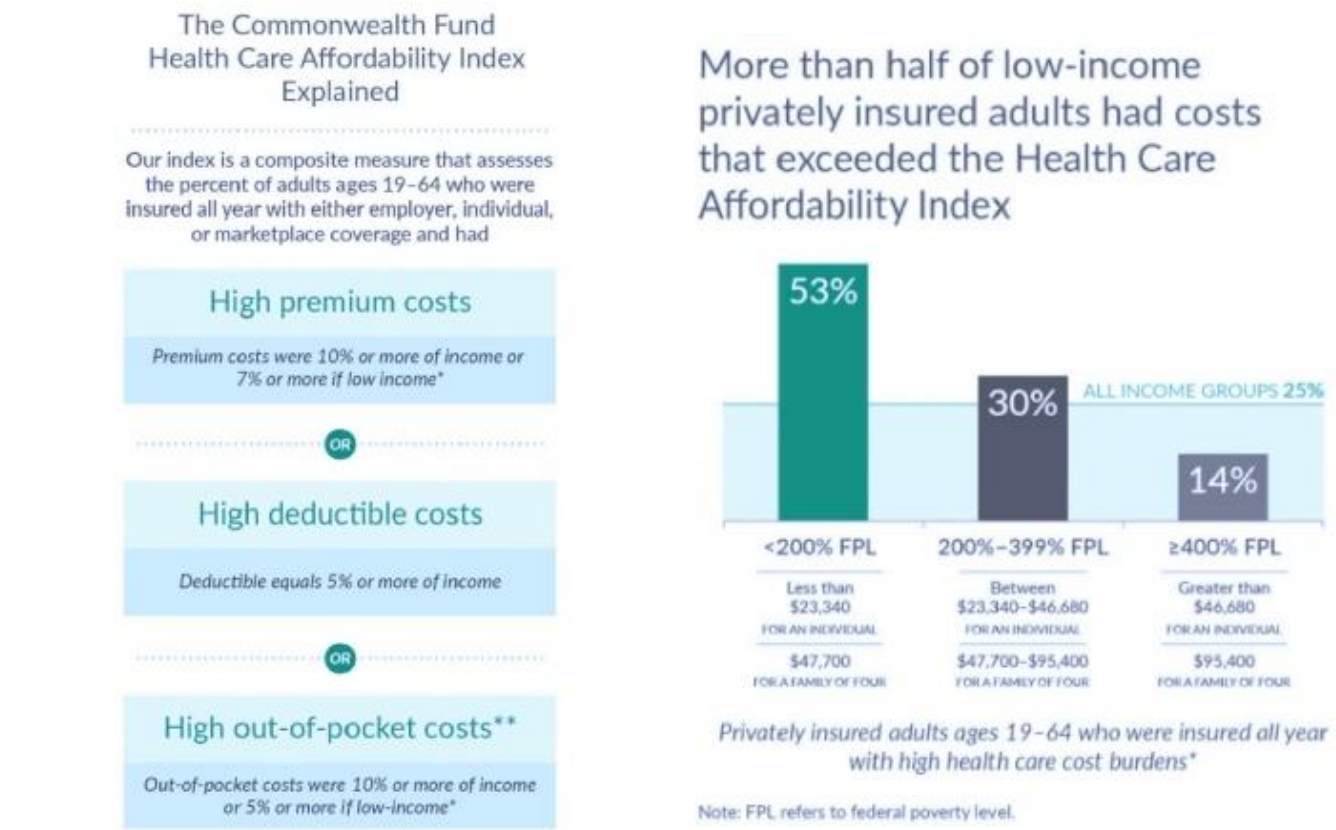

Privately insured adults ages $19-64$ who were insured all year with high health care cost burdens ${ }^{*}$

Note: FPL refers to federal poverty level.

http://www.commonwealthfund.org/publications/press-releases/2015/nov/commonwealth-fund-health-care-affordability-index

Figure 3. Healthcare unaffordability according to the Commonwealth Fund.

The affordability of insurance plans purchased on health exchanges, including those receiving premium subsidies, is also of concern. Premium costs are expected to rise $22 \%$ in 2017, during a period of declining choice as Aetna, United Health, and others have withdrawn from several major markets. Annual out-of-pocket payments of $\$ 7,150$ for individuals and $\$ 14,300$ are unaffordable for those who are ineligible for Medicaid and earning 1.4 to 4.0 times the Federal Poverty Level (Table 1).

Table 1. High out-of-pocket limit in health exchange plans. 
1733. Gruber. Grading https://doi.org/10.30953/tmt.v1.49

Page 7 of 23

\begin{tabular}{|c|c|c|c|c|}
\hline & Bronze & Silver & Gold & Platinum \\
\hline${ }^{1}$ Actuarial Value & $60 \%$ & $70 \%$ & $80 \%$ & $90 \%$ \\
\hline${ }^{2}$ Specialty Visit Co-pay & $\$ 65$ & $\$ 56$ & $\$ 44$ & $\$ 29$ \\
\hline $\begin{array}{c}{ }^{3} \text { Average Preferred Brand Name } \\
\text { Drug Copayment }\end{array}$ & $\$ 56$ & $\$ 47$ & $\$ 39$ & $\$ 31$ \\
\hline $\begin{array}{l}{ }^{3} \text { Average Specialty Drug } \\
\text { Copayment }\end{array}$ & $\$ 191$ & $\$ 166$ & $\$ 158$ & $\$ 127$ \\
\hline${ }^{4}$ Annual Out of Pocket & $\begin{array}{l}\$ 7,150 \text { Individual } \\
\$ 14,300 \text { Family }\end{array}$ & $\begin{array}{r}\$ 7,150 \text { Individual } \\
\$ 14,300 \text { Family }\end{array}$ & $\begin{array}{l}\$ 7,150 \text { Individual } \\
\$ 14,300 \text { Family }\end{array}$ & $\begin{array}{r}\$ 7,150 \text { Individual } \\
\$ 14,300 \text { Family }\end{array}$ \\
\hline
\end{tabular}

Note: Out-of-pocket maximums only apply to covered essential benefits. So if your plan doesn't cover a service, or the service isn't an essential benefit it may not count toward your maximum. Out of pocket maximums adjusted for income below $250 \%$ of the Federal Poverty Level. If household income is $100-200 \%$ of FPL, the out-of-pocket limit for an Individual will be no more than $\$ 2,250$ or $\$ 4,500$ for a family.

1http://i.investopedia.com/content/health_insurance_plans.jpg

${ }^{2}$ Kaiser Family Foundation

${ }^{3}$ http://images.alfresco.advanstar.com/alfresco images/pharma/2014/12/29/0163c817-3845-45cd-95f4-04d8130b2bb9/ NortonBloglmage-800x654.png

${ }^{4}$ http://obamacarefacts.com/health-insurance/out-of-pocket-maximum/

High out-of-pocket costs also adversely affect health outcomes due to the avoidance of necessary care. High deductible plans, in theory, suggest greater selectivity of providers and the site of service. However, limited price and quality transparency, combined with inadequate patient literacy, may not result in the intended consequence. A Gallup Poll from 2013 suggests the possible occurrence of negative healthcare consequences in one-third of avoided visits (Figure 4). 
1733. Gruber. Grading

https://doi.org/10.30953/tmt.v1.49

Page 8 of 23

Within the last 12 months, have you or a member of your family put off any sort of medical treatment because of the cost you would have to pay?

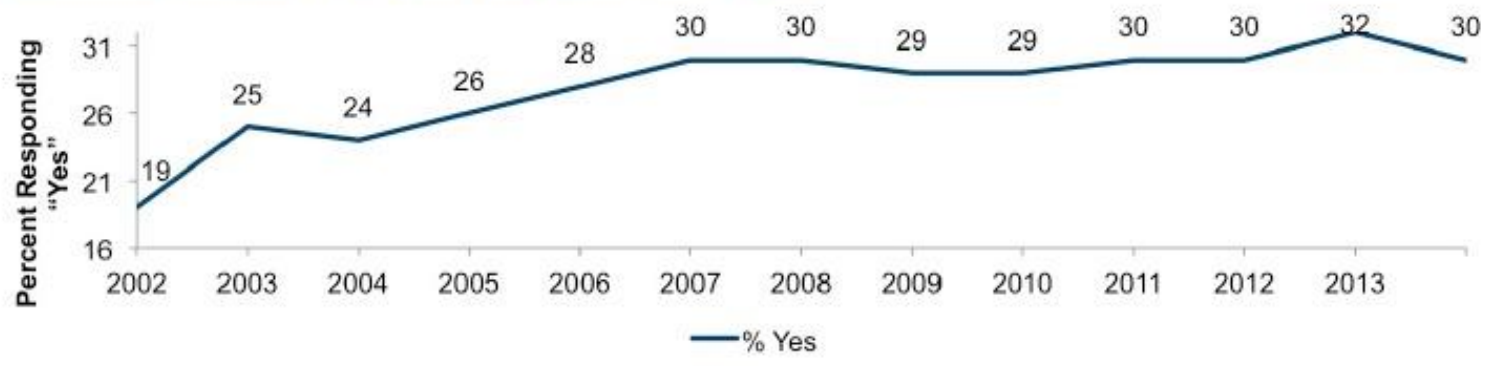

When you put off this medical treatment, was it for a condition or illness that was - very serious, somewhat serious, not very serious, or not at all serious?

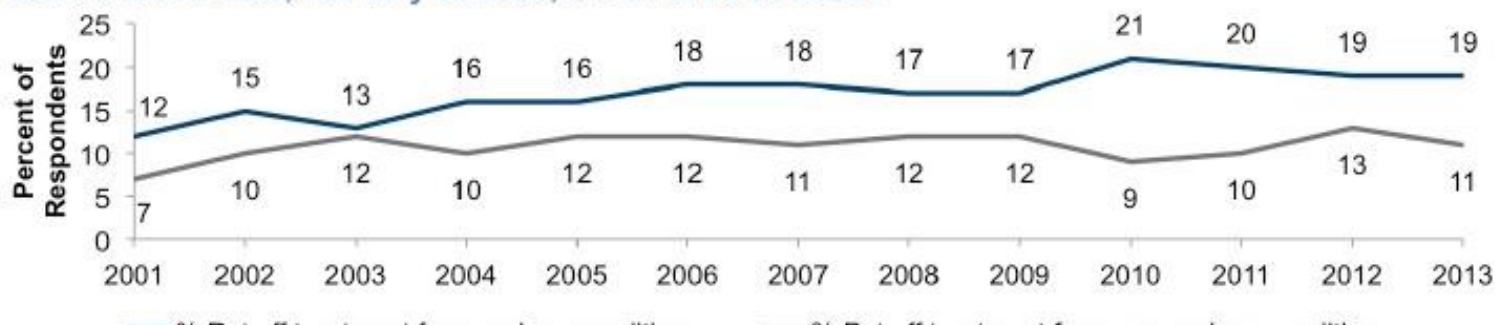

— $\%$ Put off treatment for a serious condition $\quad-\%$ Put off treatment for a non-serious condition

Source: GALLUP Well-Being. Costs Still Keep 30\% of Americans From Getting Treatment. December 9, 2013.

Figure 4. Higher costs affect utilization of health services.

A December 2014 New York Times article entitled "Health Spending Rises Only Modestly" highlighted 2013 as the year with the lowest rate of increase in healthcare spending (3.1\%) since recording began in $1960 .{ }^{10}$ One day earlier, the White House published the following statement on its blog: "Today's data make it increasingly clear that the recent slow growth in the cost of health care reflects more than just the 20072009 recession and its aftermath, but also structural changes in our health care system, including reforms made in the Affordable Care Act." 11

The celebration was premature and factually incorrect. Factors such as the Great Recession, significant cost shifting by employers and continued generic drug penetration led to the slowdown in healthcare spending; net structural changes 
1733. Gruber. Grading https://doi.org/10.30953/tmt.v1.49 Page 9 of 23

instituted by the PPACA were inconsequential. In actuality, value-based CMS initiatives were more than offset by increased coverage, provider and insurer consolidation, and explosive growth in specialty and branded drug pharmaceutical pricing, thereby setting the stage for an acceleration of healthcare spending.

In 2014 , overall health spending grew by $5.3 \%$, whereas per capita spending increased by $4.4 \%$. The comparable figures for 2015 were 5.8 and $5.0 \%$, respectively. ${ }^{12}$ The latest projections from CMS forecast even higher growth through 2025 (Figure 5).

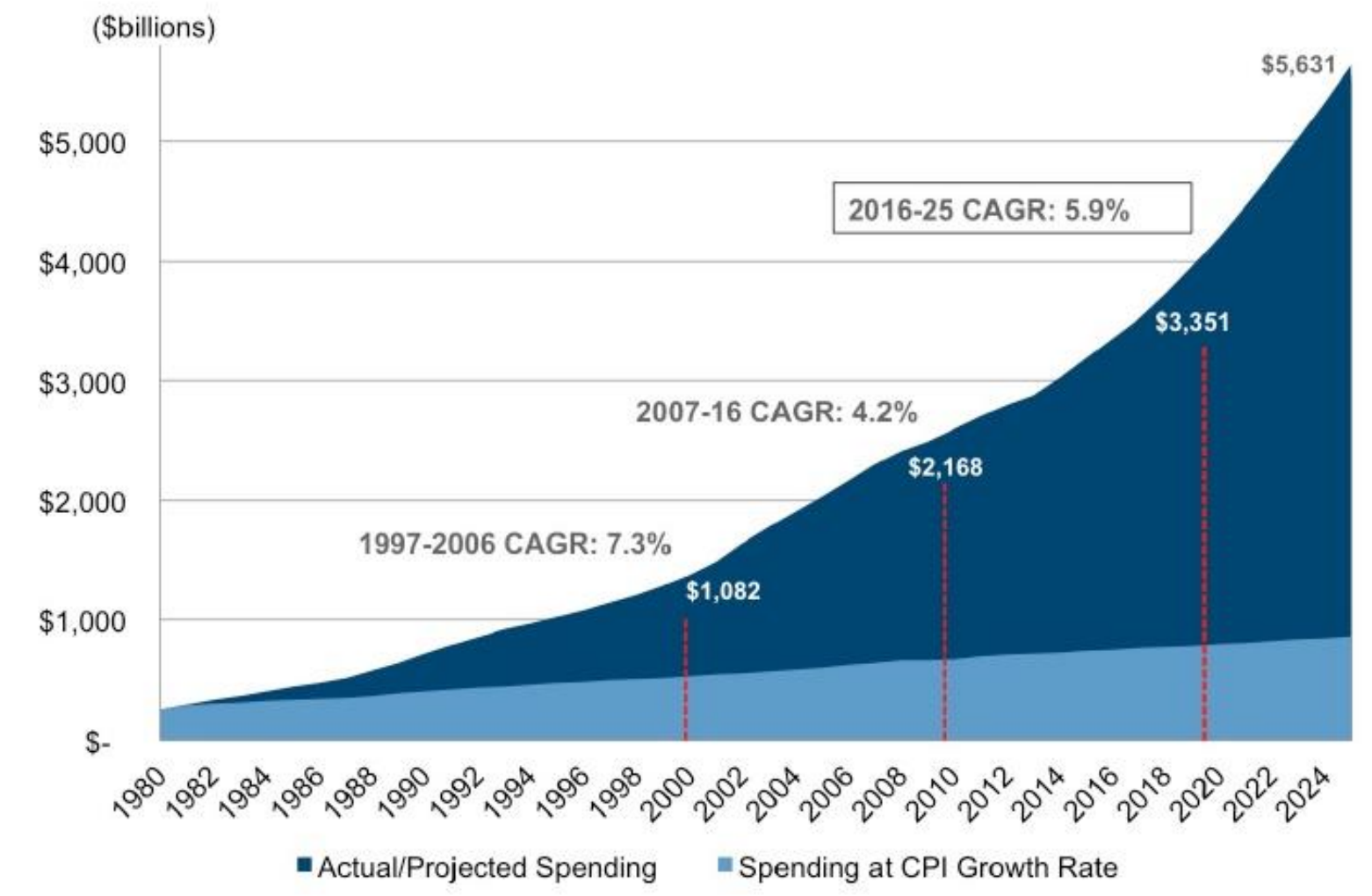

Sources: CMS National Health Expenditures, BLS CPI Inflation Calculator. https:/www.cms.gov/Research-Statistics-Data-andSystems/Statistics-Trends-and-Reports/NationalHealthExpendData/NationalHealthAccountsProjected.html

Figure 5. National healthcare expenditures: 1980-2025.

Any discussion about healthcare cost containment is necessarily also a conversation about entitlement reform, the federal budget and the national debt (Figure 6). In 2016- 
1733. Gruber. Grading https://doi.org/10.30953/tmt.v1.49

Page 10 of 23

2026, according to the $\mathrm{CBO}$, mandatory federal outlays are forecast to increase from $\$ 2.5$ to $\$ 4.1$ trillion (CAGR: $5.3 \%$ ), discretionary outlays from $\$ 1.2$ to $\$ 1.4$ trillion (CAGR: $1.8 \%$ ) and interest from $\$ 255$ to $\$ 830$ billion (CAGR: $12.5 \%$ ). Medicare ( $\$ 596$ billion) and Medicaid ( $\$ 261$ billion) alone account for $51 \%$ of the federal increase in mandatory outlays, whereas Social Security accounts for $42 \%$. A deficit of $-\$ 544$ billion in 2016 is forecast to reach $-\$ 1,366$ billion in 2026 , leading to an increase in the debt held by the public of $\$ 23.8$ trillion. ${ }^{13}$ Deficit spending and the subsequent rise in debt are unsustainable.
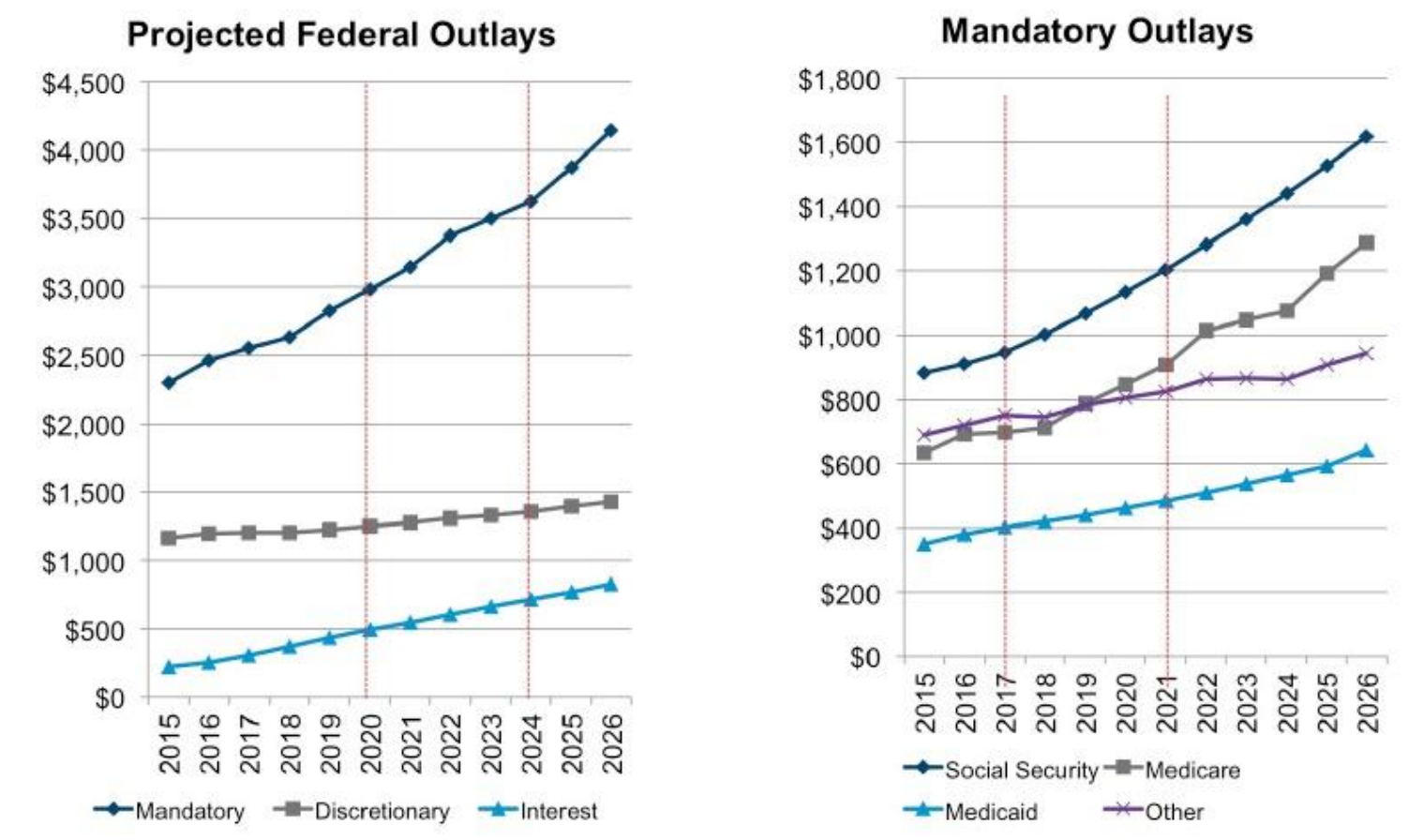

https:/www.cbo.gov/sites/defaultfiles/114th-congress-2015-2016/reports/51129-2016Outlook.pdf

Figure 6. Projected federal outlays, 2016-2016.

The CBO projections were generated prior to the November election. A report by the nonpartisan Committee for a Responsible Federal Budget estimates that tax reform plans proposed by candidate and now President Trump would, during the next decade, reduce individual and business taxes by $\$ 4.5$ trillion and increase the deficit by $\$ 5.3$ trillion; the debt held by the public would reach $105 \% .^{14}$ 
In the Grading Obamacare on the Fundamentals of Care Delivery, A\&M provides additional fact-based rationale for grading the impact of Obamacare on the following areas:

- Managing competition: Consolidation, as measured by standard measures of competition such as the Herfindahl-Hirschman Index (HHI), leads to higher baseline prices and portends a higher rate of spending growth in the future.

- Increasing clinical effectiveness: Defined as the application of the best knowledge, derived from research, clinical experience and patient preferences to achieve optimum processes and outcomes of care for patients. Systematic reviews - the basis of evidence-based medicine-can show which treatments and prevention methods have been proven to work and what remains unknown.

- Improving efficiency: A measure of the relationship between a specific level of healthcare quality and the resources (intensity) used to provide that care, i.e., the production of the desired effects or results with minimum waste of time, effort or skill.

- Facilitating payment reform: Involves the use of financial incentives and disincentives to facilitate the transition from fee-for-service (FFS) payment models - providers receiving a specific amount of compensation in exchange for providing a patient with a specific service - to value-based payment systems focused on the provision of high-quality, efficient care.

- Enhancing the experience of care: Reflects occurrences and events that happen independently and collectively across the continuum of care. Embedded within patient experience is setting expectations, focusing on the specific needs of individual patients, and engaging patients and their caregivers.

In these areas, the record is mixed, if not overall negative. In large part, the PPACA has led to a consolidation of providers and payers, with resultant increased prices. PPACA initiatives have shown only modest impact on clinical outcomes and overall improvements in the health of the general population. Although the PPACA created some new payment models (Accountable Care Organizations) and furthered Medicare's 
1733. Gruber. Grading

https://doi.org/10.30953/tmt.v1.49

Page 12 of 23

value-based purchasing initiatives, the record on improving efficiency or payment models is negative to mixed. Finally, preliminary data suggests that the PPACA has not increased overall patient / consumer satisfaction with the healthcare delivery system.

\section{“Trumpcare": What's Next?}

Unlike other recent presidential candidates who issued lengthy policy prescriptions, and even published books, as part of their campaigns (e.g., 1992 Bill Clinton, Putting People First; 2000, George W. Bush, A Fresh Start for America; 2008, Barack Obama, The Audacity of Hope; 2016, Hillary Clinton, Stronger Together, President Trump's campaign provided limited insight into its healthcare policy view, other than sustained promises that Obamacare will be repealed, that any new system for the uninsured would have more flexibility, and that the Trump administration would stand by the federal government's historical commitment to Medicare.

Since the election, the Trump transition team has outlined on a single webpage the tenets that will guide its healthcare policy, which in most respects mirror what the candidate said on the campaign trail. The challenge is always to distinguish between campaign trail rhetoric and actual policy position.

One position that has been a constant since the inception of the Trump campaignindeed with the inception of the campaigns of all the Republican candidates-has been an absolute commitment to "repeal and replace" Obamacare. From that perspective, a legislative bill, any bill, must be put forth by the Republican Congress and the Trump administration that is styled as a repeal bill. But on a total repeal of all provisions of Obamacare, already here the President Trump has hedged a bit and has offered that some of the most popular provisions of the PPACA - pre-existing condition bans and adult children coverage on a parent's healthcare policy—will be maintained; all other provisions (e.g., subsidies, healthcare exchanges, uniform mandated benefits, Medicare "surtax") are subject to being jettisoned. ${ }^{15}$ Trump administration authorized "replacement bills" might include:

- An increased reliance on Health Savings Accounts (HSAs). 
1733. Gruber. Grading

https://doi.org/10.30953/tmt.v1.49

Page 13 of 23

- The elimination of uniform, "minimum" and/or "essential" health insurance benefit provisions required by the federal government, i.e., allowing state insurance commissioners to determine the specific benefits to be included in an individual (not employer sponsored) healthcare plan.

- Changes to federal law permitting individual health insurance policies to be sold across state lines.

- Expansion (or establishment) of high-risk pools patients, possibly state-based, to assist individuals with high-cost chronic conditions who otherwise cannot access insurance on an individual market.

- Elimination of any mandated benefits (e.g., birth control) that might conflict with beliefs of religious organizations or employers.

The Trump transition healthcare position has also called for:

- Additional funding for healthcare research

- Food and Drug Administration (FDA) reforms to speed approval of innovative drugs and medical products

Presumably, a "repeal and replace" bill will eliminate or significantly alter the Medicaid expansion provided under the PPACA. The Trump administration is committed to devolving authority from the federal government to states and allowing individual states to design and administer their own Medicaid programs. Most pronounced is the administration's desire to seek more Medicaid waiver programs and, possibly, to exchange Medicaid expansion for block grants. Given Vice President Mike Pence's position on Medicaid, it is highly likely that any Trump administration "replace" plan will include some kind of Medicaid block granting provision.

As a candidate, President Trump frequently announced that the Medicare program was more or less a "sacred promise" to beneficiaries. Although the Trump transition website mentions a desire to "modernize Medicare," any movement from a defined benefit to defined contribution plan, as proposed by House Speaker Paul Ryan, is unlikely to occur, if it is to occur at all, in the early part of a Trump administration. The Trump 
1733. Gruber. Grading

https://doi.org/10.30953/tmt.v1.49

Page 14 of 23

administration will, however, likely promote the expansion of market-based solutions such as continuing growth in Medicare Advantage plan enrollment.

The phrase "personnel is policy" was popularized during the Reagan administration. ${ }^{16}$ This maxim is clearly applicable to President Trump, who remains sparing on details around replacement legislation for the PPACA and Medicaid / Medicare reform. Any policy predictions must include consideration of previously advocated healthcare policy positions by Trump appointees and key Republican legislators.

Because President Trump believes himself to be an astute evaluator of talent, history suggests that once he trusts and/or hires a person, that individual will have significant latitude in his or her position. In that respect, every Trump administration appointment appears to have his personal imprimatur.

Four key healthcare-related personnel picks demonstrate the president-elect's intentions:

Foremost is the selection of Mike Pence to be Vice President. Pence, the Governor of Indiana and a former Congressman and leader of the Republican Policy Conference, may emerge as one of the most influential vice presidents in history, even more influential than Vice President Dick Cheney. Pence's influence is particularly noted by his appointment as the chairman of President Trump's transition team. This transition leadership position means that most, if not all, hires will have his stamp of approval. The first two key healthcare appointments demonstrate Pence's influence, as both appointees have historic relationships with him: Tom Price, M.D., as Secretary of Health and Human Services and Seema Verma, a former healthcare policy consultant and author of the Indiana Medicaid waiver program, as the Administrator of CMS.

The selection of Dr. Price as HHS secretary, a position often given to a governor with executive experience (e.g., Kathleen Sebelius, Michael Leavitt, Tommy Thompson), highlights President Trump's desire for a secretary who literally knows how to write 
1733. Gruber. Grading

https://doi.org/10.30953/tmt.v1.49

Page 15 of 23

"repeal and replace" legislation for the PPACA and shepherd it through Congress. The president-elect also apparently believes that doctors, not bureaucrats, matter and being an orthopedic surgeon further qualifies Dr. Price as an administrator of healthcare policy.

The appointment of Ms. Verma as Administrator of CMS reflects Vice President Pence's strong preference for the use of innovative Medicaid state waivers and a possible shift to a system of block grants for Medicaid, rather than the traditional federal/state pro rata cost sharing model.

Another significant personnel choice impacting healthcare is Reince Priebus as White House Chief of Staff. Although President Trump campaigned as the consummate Washington "outsider," with Priebus as his Chief of Staff, he has someone with significant Washington political experience. Mr. Priebus has a close, personal relationship with Speaker Paul Ryan, suggesting that passing legislation is more important to Trump than stoking an internecine party war.

The Price, Ryan, and Priebus trio will likely be the primary designers and movers of "repeal and replace" legislation through Congress. Added to this team is Senator Mitch McConnell, Majority Leader of the Senate, considered an expert on the intricacies of Senate rules and procedures, based on more than 32 years of experience. This knowledge will be essential, especially if the Trump administration and the Republican Congressional leadership elect to proceed on "repeal and replace" through the budget reconciliation process, bypassing the Senate's 60 vote or "filibuster" rules.

Lastly, demonstrating that any internecine party wars are over and that "running the trains on time" takes priority, President Trump has reached out to a number of HHS staffers from the George W. Bush administration-Andrew Bremberg, Paula Stannard, Eric Hargan, Scott Gottlieb, M.D., and Nina Owcharenko-to ensure a smooth transition by deputizing former political insiders already familiar with the mechanics necessary to manage the sprawling HHS bureaucracy and its $\$ 1.1$ trillion budget. 
1733. Gruber. Grading

https://doi.org/10.30953/tmt.v1.49

Page 16 of 23

\section{The First 60 Days to Six Months}

How do the general themes outlined by the Trump transition team - most importantly, "repeal and replace" but also Health Savings Accounts, Medicaid block waivers, the sale of health insurance across state lines and other items - get translated into a robust policy statement and legislative package on a timely basis?

Both HHS Secretary Dr. Price and Speaker Ryan have already generated alternative legislative approaches to "repeal and replace." Dr. Price first introduced HR 2300, also known as the "Empowering Patients First Act," in June 2013 and reintroduced the Act in May 2015 to "fully repeal Obamacare and start over with patient-centered solutions." ${ }^{17}$ 18

Speaker Ryan's plan for "repeal and replace" of the PPACA, although not committed to specific legislative language, contains similar provisions to Dr. Price's Empowering Patients First Act, including tax credits, use of HSAs and high-risk pools.

For Republican budget hawks, such as Speaker Ryan, a key looming question will be: How much of the federal budget will be committed to subsidies to purchase health insurance, even if the subsidies come by way of a refundable tax credit or voucher from the federal government, rather than a check directly to an insurance company? Since a Republican "repeal and replace" bill may eliminate many of the funding mechanisms of the PPACA - Medicare surtax and the various taxes on employer-based plans - the cost of a repeal and replace with tax credits may add to the federal budget deficit.

\section{Our Prediction}

In some form or fashion, a bill will be enacted by Congress—and signed by President Trump—in 2017 that "repeals" and "replaces" the Affordable Care Act.

- Popular ACA provisions-pre-existing condition limitations and children on parents' health plans through age 26 -will likely be maintained. 
1733. Gruber. Grading

https://doi.org/10.30953/tmt.v1.49

Page 17 of 23

- Health exchange subsidies are likely to be eliminated and replaced by advance, "refundable" tax credits or voucher-like instruments.

- Insurers will be allowed to create and sell all types of individual health insurance products, irrespective of a minimum, essential benefits package: high deductible, catastrophic to high-premium, full-coverage plans.

- Insurers will be allowed to sell health insurance across state lines

- Use of Health Savings Accounts (HSAs) will be expanded.

- High-risk pools will be created or expanded for individuals with high-cost conditions unable to find health insurance.

- Medical malpractice reform will only happen if it can get past the 60-vote filibuster threshold in the Senate, a difficult task.

"Repeal and replace" (or "repeal and delay") will occur prior to any legislative changes to Medicare or Medicaid. However, the issue of Medicaid expansion (or block grants) could become part of the budget reconciliation process.

Even without legislative changes to Medicare and Medicaid, however, the Trump administration will have significant regulatory authority at HHS / CMS to:

- Change Medicare provider payments (hospitals, physician, skilled nursing facilities, home health, etc.)

- Eliminate or change CMS quality and payment reform initiatives such as valuebased purchasing, hospital acquired condition, re-admission, episode payment model, Accountable Care Organizations (ACOs) and the Medicare Access and CHIP Reauthorization Act (MACRA)

- Change Medicare Advantage payment rates, oversight, rules, etc.

- Approve new Medicare waiver projects

- Approve new Medicaid waiver projects giving more flexibility to the states 
1733. Gruber. Grading

https://doi.org/10.30953/tmt.v1.49

Page 18 of 23

Bottom line: significant activity is likely from CMS if Secretary Price and CMS Administrator Verma following approved by the Senate.

\section{Winners and Losers}

The winners and losers are difficult to predict with certainty at this early stage, but broad outlines of "repeal and replace" (i.e., Pricecare, Ryancare) appear to be emerging:

Federal government: Healthcare spending is forecast by CMS to reach $\$ 5.6$ billion by 2026 , reflecting a compound growth rate of $5.9 \%$. The forecast incorporates the impact of ongoing value-based payment reform initiatives. Any overall changes to the latter, inclusive of a slowdown in the timing of implementation and/or its financial impact (e.g., penalties) will result in even higher healthcare spending. Improving the efficiency and effectiveness of healthcare delivery must remain a strategic priority. Elimination of the CMS Innovation Center would send a "strong" signal to providers regarding the future of payment reform. Elimination of the ACOs model is not deemed by A\&M to be a major loss due to its uncertain value.

States: 31 states and Washington, D.C., have expanded Medicaid, whereas 19 states have not. The federal government paid $100 \%$ of the incremental costs associated with expansion in 2014-16, and will pay 95\% in 2017-19 and 90\% thereafter. Block grants equivalent to the incremental federal expenditures in states with Medicaid expansion (that contain inflationary increases) will be necessary to remain "whole." States that have not expanded Medicaid will not be significantly affected by the elimination of Medicaid federal subsidies (beyond the average Federal Medical Assistance Match Rate of $57 \%$ ). A change in the Medicaid block grant formula to a federal per capita calculation adjustment would significantly impact states with high level of spending and benefit lower spending states. Reducing federal oversight on state Medicaid programs via the elimination and/ or reduction in waiver requirements may or may not be beneficial, based on the specifics of the state program. 
1733. Gruber. Grading

https://doi.org/10.30953/tmt.v1.49

Page 19 of 23

Hospitals: Obamacare has clearly benefited hospitals in states with Medicaid expansion due to the increase in coverage and a reduction in charity care. Hospitals have also benefited by the delay in offsetting Medicare and Medicaid DSH reductions. An internal analysis by A\&M of safety net hospitals with Low Income Utilization Rates (LIUR) $>25 \%$, the threshold for the receipt of Medicaid DSH payments, highlights an average difference in EBITDA of $\$ 61$ million (favorable) to hospitals within states that expanded Medicaid. In states without Medicaid expansion, Obamacare will negatively affect operating performance based on the impending reduction in Medicare and Medicaid DSH payments.

Post-acute care providers: A reduction in Medicare fee-for-service reimbursement, combined with increased Medicare Advantage penetration, has led to lower profit margins for skilled nursing facilities and home health agencies. Any acceleration in Medicare spending is likely to lead to additional reductions in either the rate of reimbursement growth, the absolute level or reimbursement or coverage requirements. Value-based payment initiatives are essential to improve operational efficiency and effectiveness.

Physicians: Elimination of value-based physician payments via MACRA would create a real issue with the manner in which Congress tried to fix the annual Medicare payment update based on the sustainable growth rate (SGR) system. A payment system that promotes significant income disparities between specialists who might earn on average $\$ 750,000$ and primary care internists earning $\$ 224,000$ will contribute to the growing shortage of the latter despite their far greater contribution to population health and the total cost of care.

Insurance companies: Medicare Advantage and Medicaid Managed Care plans will likely be supported by the new administration, a positive for insurance companies focused in those areas. The availability of health plans across state lines is likely to further the competitive position of the largest insurers better able to rapidly form 
1733. Gruber. Grading

https://doi.org/10.30953/tmt.v1.49

Page 20 of 23

provider networks and price coverage based on actuarial assumptions. The elimination of health exchanges may herald a return of the health insurance broker model.

Employers: Elimination of the employer insurance mandate for companies with more than 50 employees, minimum coverage requirements and the Cadillac Tax will be welcomed by many businesses.

Individuals: Despite the likelihood that changes to coverage are unlikely for preexisting conditions and under 26-year-old population, individuals remained challenged by access and affordability issues. Dr. Price's proposal for "continuous coverage exclusion" might allow insurers to either charge a higher price or exclude coverage based on preexisting conditions for up to 18 months only if a gap in coverage of greater than 63 days exists. Many groups will be concerned if "repeal and replace" results in discontinuation of mandated reproductive health benefits, a loss of coverage for preventive health services and a reduction and/or loss of health exchange subsidies. High-income households may benefit if the Medicare surtax is eliminated.

Pharmaceutical companies: Depends on whether drugs can be negotiated by Medicare, shipped cross-border from Canada or elsewhere, and cost-effectiveness data can be required for the reimbursement of newly approved (oncology) drugs by Medicare. Pharmaceutical (and medical product) companies have spent more money on federal lobbying in 1998-2016, $\$ 3.5$ billion than any other industry; the 2015 figure is \$241 million.

\section{In Summary}

As a $\$ 3.4$ trillion enterprise with the government funding nearly one-half of total expenditures, healthcare is not amenable to a "deal" that does not consider the underlying inefficiency and ineffectiveness of care delivery. Projected national health expenditures of $\$ 5.4$ trillion ( $\$ 16,032$ per capita) in 2025, representing 20.1\% of GDP, are a threat to U.S. competitiveness, aging Baby Boomers and the financial security of 
1733. Gruber. Grading

https://doi.org/10.30953/tmt.v1.49

Page 21 of 23

the middle class. A continued shift from fee-for-service (volume) to value, initiated by President Obama under the PPACA, is a requisite for fundamental change.

David Gruber, MD, MBA is a Managing Director and the Director of Research with the Alvarez \& Marsal Healthcare Industry Group in New York, specializing in strategy, commercial due diligence, analytics and new ventures. Dr. Gruber brings 3 years of diversified healthcare experience as a consultant, corporate executive, Wall Street analyst and physician.

Peter Urbanowicz, JD, is a Managing Director with the Alvarez \& Marsal Healthcare Industry Group in Washington, D.C., and leads the firm's healthcare compliance practice. He was formerly deputy general counsel of the United States Department of Health and Human Services and then general counsel of Tenet Healthcare Corporation (NYSE: THC). Mr. Urbanowicz has 25 years of experience in addressing challenging healthcare issues in government and private industry

"Reprinted with permission, (C) 2016 Alvarez \& Marsal Holdings, LLC. All rights reserved. For more information, visit www.alvarezandmarsal.com."

References

1. Gruber D and Urbanowicz. "Repeal and Replace": What's Next. TMT. January 2017, Volume 2, Issue 1. URL: http://www.telhealthandmedtoday.com/repealand-replace-whats-next/. Accessed 2/15/17.

2. Gruber D and Urbanowicz. Obamacare: Coverage without Cost Containment. TMT. January 2017, Volume 2, Issue 1. http://www.telhealthandmedtoday.com/obamacare-coverage-without-costcontainment/. Accessed 2/15/17. 
1733. Gruber. Grading

https://doi.org/10.30953/tmt.v1.49

Page 22 of 23

3. Gruber D and Urbanowicz. Grading Obamacare on the Fundamentals of Care Delivery. TMT. January 2017, Volume 2, Issue 1. URL:

http://www.telhealthandmedtoday.com/grading-obamacare-on-the-fundamentalsof-care-delivery/. Accessed: 2/15/17.

4. CMS National Health Expenditures. https:// www.cms.gov/Research-StatisticsData-and-Systems/Statistics-Trends-andreports/NationalHealthExpendData/NationalHealthAccountsProjected.html. Acce ssed: $2 / 15 / 17$.

5. AAMC. New physician workforce projections show the doctor shortage remains significant. 2015.. URL: https://www.aamc.org/newsroom/newsreleases/426166/20150303.html.

6. Kaiser Family Foundation.

7. Congressional Budget Office. Estimates for the insurance coverage provisions of the Affordable Care Act updated for the recent Supreme Court decision. Table 3; July 2012. https://www.cbo.gov/publication/51385

8. Posey KG. Household Income: 2015. Us Census Bureau. 2016. https://www.census.gov/content/dam/Census/library/publications/2016/demo/acs br15-02.pdf. Accessed: 2/15/17.

9. NPR / Robert Wood Johnson Foundation / Harvard T.H. Chan School of Public Health poll "Patients' Perspectives on Health Care in the United States." Interviews were conducted via telephone (landline and cellphone) in English and Spanish. Sept. 8-Nov. 9, 2015. http://www.npr.org/sections/healthshots/2016/03/08/468892489/medical-bills-still-take-a-big-toll-even-withinsurance

10. New York Times. Health Spending Rises Only Modestly; Dec. 4, 2014. https://www.nytimes.com/2014/12/04/us/pace-of-health-care-cost-increases-fallsto-a-54-year-low. html?_r=0

11. White House Blog; Council of Economic Advisers; Dec. 3, 2014.

12. Martin $A B$, Hartman $M$, Washington $B$, Catlin $A$. National health spending: Faster growth in 2015 as coverage expands and utilizations increases. Health Affairs. 
1733. Gruber. Grading

https://doi.org/10.30953/tmt.v1.49

Page 23 of 23

2016. http://content.healthaffairs.org/content/early/2016/11/22/hlthaff.2016.1330, Accessed: 2/15/17.

13. The Budget and Economic Outlook: 2016 to 2026.

https://www.cbo.gov/sites/default/files/114th-congress-2015-2016/reports/511292016Outlook.pdf.

14. Promises and price tags: an update. Committee for a Responsible Federal Budget. 2016. URL: http://crfb.org/papers/promises-and-price-tags-preliminaryupdate. Accessed: 2/15/17.

15. Donald Trump On '60 Minutes': President-Elect Says He'll Keep Elements of Obamacare. http://deadline.com/2016/11/ donald-trump-obamacare-hillaryclinton- 60-minutes-interview-lesley-stahl-video-1201853375/.

16. "Personnel is policy" blog post entry from Barry Popik; March 13, 2013. http://www. barrypopik.com/index.php/new_york_city/entry/personnel_is_policy.

17. Press release: Price introduces Empowering Patients First Act; May 13, 2015. https://tomprice.house.gov/HR2300.

18. H.R. $2300\left(113^{\text {th }}\right)$ : Empowering patients first act of 2013. Govtrack. 2013. https://www.govtrack.us/congress/bills/113/hr2300. Accessed: 2/15/17.

Category: Opinion

Tags: affordability of care, Affordable Care Act, Centers for Medicare \& Medicaid Services, cost containment, David Gruber, grading Obamacare, Medicare, Medicare, Obamacare, Peter Urbanowicz, Trumpcare, winners and losers 